\title{
A Biostimulant Preparation of Brown Seaweed Ascophyllum nodosum Suppresses Powdery Mildew of Strawberry
}

\author{
Sruti Bajpai ${ }^{1}$, Pushp Sheel Shukla ${ }^{1}$, Samuel Asiedu ${ }^{2}$, Kris Pruski ${ }^{2}$, and Balakrishnan Prithiviraj (iD ${ }^{1 *}$ \\ ${ }^{I}$ Marine Bio-products Research Laboratory, Department of Plant, Food and Environmental Sciences, Dalhousie \\ University, Truro, NS B2N 5E3, Canada \\ ${ }^{2}$ Department of Plant, Food and Environmental Sciences, Dalhousie University, Truro, NS B2N 5E3, Canada
}

(Received on March 26, 2019; Revised on May 17, 2019; Accepted on May 21, 2019)

Strawberry, an important fruit crop, is susceptible to a large number of pathogens that reduce fruit quality and productivity. In this study, the effect of a biostimulant prepared from Ascophyllum nodosum extract (ANE) $(0.1 \%, 0.2 \%$, and $0.3 \%)$ was evaluated on powdery mildew progression under greenhouse and field conditions. In the greenhouse, application of $0.2 \%$ ANE showed maximum reduction in powdery mildew progression as compared to the control. Forty-eight hour post-inoculation, foliar spray of $0.2 \%$ ANE reduced spore germination by $\mathbf{7 5 \%}$. Strawberry leaves sprayed with ANE showed higher total phenolic and flavonoid content in response to powdery mildew infection. Furthermore, application of ANE elicited defense response in strawberry plants by induction of defense-related enzymes, such as phenylalanine ammonia lyase, polyphenol oxidase, and peroxidase activity. In field conditions, foliar spray of $0.2 \%$ ANE showed a reduction of $37.2 \%$ of natural incidence of powdery mildew infection as compared to the control. ANE sprayed plant also reduces the severity of powdery mildew infection under natural conditions. These results indicate that application of ANE induces the strawberry plant's active defense against powdery mildew infection by induction of

*Corresponding author.

Phone) +1-902-893-6036, FAX) +1-902-893-1404

E-mail) bprithiviraj@dal.ca

ORCID

Balakrishnan Prithiviraj

https://orcid.org/0000-0002-9822-5261

(c) This is an Open Access article distributed under the terms of the Creative Commons Attribution Non-Commercial License (http:// creativecommons.org/licenses/by-nc/4.0) which permits unrestricted noncommercial use, distribution, and reproduction in any medium, provided the original work is properly cited.

Articles can be freely viewed online at www.ppjonline.org. secondary metabolism and regulating the activities of defense-related enzymes.

Keywords : Ascophyllum nodosum extract, phenylalanine ammonia lyase, Podosphaera aphanis, powdery mildew, strawberry

Handling Editor : Park, Chang-Jin

Strawberry (Fragaria $\times$ ananassa) is an important small fruit cultivated globally. In Canada, strawberry is a significant berry crop with production totaling 19,372 metric tonnes and a market value of $\$ 82.5$ million (Statistics Canada, 2015). A number of biotic and abiotic stresses affect strawberry yield and fruit quality. Among biotic factors, fungal diseases are major limiting factors that cause significant losses in strawberry productivity (Elmhirst, 2005; Nezhadahmadi et al., 2015).

Powdery mildew caused by a bio-trophic fungal pathogen Podosphaera aphanis (syn. Sphaerotheca macularis) (Kiss, 2003), is a major limiting factor in strawberry production worldwide (Maas, 1998). The asexual stage of this pathogen on strawberries was first reported in 1854 in the United Kingdom (Corke and Jordan, 1978). Powdery mildew infects all parts of the strawberry plant including leaf, fruit, peduncle, stem, and runners. Initial symptoms of powdery mildew appear as a white powdery formation on the leaf surface followed by an upward curling of leaves, white mycelia on the upper surface of the leaf and lower leaves turning reddish in color (De Cal et al., 2008). $P$. aphanis causes severe damage to the leaves and can reduce photosynthetic activity due to dense mycelial growth causing necrosis, resulting in defoliation and yield loss (Karajeh et al., 2012). Many commercially available strawberry cultivars are highly susceptible to powdery mildew, and it is 
generally suppressed by the application of fungicides such as Captan and benomyl. Only few moderately resistant varieties are available but cannot eliminate the requirement of fungicide application for disease suppression. The use of fungicides causes harmful effects on human health and the environment. Therefore, alternate eco-friendly approaches for the management of powdery mildew need to be explored.

Seaweeds are an important component of marine coastal ecosystems (Shukla et al., 2016). Seaweeds are a rich source of macro- and micronutrients, amino acids, vitamins, and growth substances that affect cellular metabolism and enhance plant growth and crop yield (Khan et al., 2009). The most commonly used seaweed as a plant biostimulant is Ascophyllum nodosum (rockweed), a brown alga widely distributed in the North Atlantic Ocean. $A$. nodosum is rich in polysaccharides (alginate, fucoidan, and laminarin), minerals and vitamins. It is also rich in bioactive compounds such as polyphenols, lipids, and proteins (Holdt and Kraan, 2011).

Resistance against pathogens can be induced in plants by elicitors (Ilangumaran et al., 2017; Mercier et al., 2001). The bioactive compounds present in various seaweed extracts elicit defense responses against pathogens (Khan et al., 2009; Sharma et al., 2014; Shukla et al., 2016). The bioactive compound present in the extract of Ascophyllum nodosum acts as an elicitor molecule and acts as pathogen-associated molecular patterns (PAMPs) (Sharma et al., 2014). These PAMPs are recognized by host transmembrane pattern recognition receptors (PRRs), which signal defense pathways of induced systemic resistance and systemic acquired resistance (Eckardt, 2008; Zipfel, 2009). The bioactive compounds present in the $A$. nodosum extracts can be used as elicitors of innate and systemic immune responses in plants (Sharma et al., 2014). Several reports suggest that A. nodosum extracts (ANE) elicit defense responses against a number of pathogens (Patier et al., 1995; Sharma et al., 2014). ANE reduces the progression of fungal diseases in greenhouse-grown cucumber and carrot which by the induction of secondary metabolism and defense-related enzymes (Jayaraj et al., 2008; Jayaraman et al., 2011). Soil application of ANE significantly reduced downy mildew of onion (Allium cepa L.) and increases crop yield (Dogra and Mandradia, 2014). Considering concerns regarding the excessive use of pesticides in horticultural crops, there is a need to develop ANE as an alternative strategy for sustainable disease management in agricultural system (ElMiniawy et al., 2014). Therefore, in the present study, we evaluated the efficacy of a plant biostimulant $A$. nodosum extract in reducing powdery mildew disease in strawberry, both in the greenhouse as well as under field conditions.

\section{Materials and Methods}

Plant material and growth conditions. Strawberry plants (Fragariae ananassa) were propagated from runners purchased from G.W. Allen Nursery (Centreville, NS, Canada), and were planted in 3-liter plastic pots filled with PROMIX (Premier Tech, QC, Canada). Plants were grown in a growth chamber with $16 / 8$-h day/night photoperiod set at a temperature of $22 \pm 2{ }^{\circ} \mathrm{C}$. These plants were watered on alternate days. The strawberry plants were irrigated with 100 $\mathrm{ml}$ of $1 \mathrm{~g} / 1 \mathrm{~N}-\mathrm{P}-\mathrm{K}(20-20-20)$ fertilizer every 3 weeks. Onemonth-old plants were used in experiments.

Isolation and maintenance of pathogen. Powdery mildew infected strawberry leaves were collected from farms in Dalhousie University, Faculty of Agriculture, Truro, NS. Strawberry plants maintained in growth chamber (16/8-h photoperiod [day/night] with $22 \pm 2^{\circ} \mathrm{C}$ ) were inoculated by tapping spores from the infected leaves, as described by $\mathrm{Li}$ et al. (2017), and conidia of $P$. aphanis from the infected leaves was used in experiments.

Preparation of ANE and treatments. ANE powder was a gift from Acadian Seaplants Ltd. (Dartmouth, NS, Canada). Three concentrations of ANE $(0.1 \%, 0.2 \%$, and $0.3 \%)$ were prepared in distilled water. The plants sprayed with distilled water served as control. Tween $20(0.02 \%)$ was added to all the solutions as a surfactant. The plants were sprayed with $100 \mathrm{ml}$ of different concentrations of ANE twice: the first treatment on the first day of the experiment, followed by a subsequent treatment on the fifth day. Each treatment consisted of six plants and the experiment was repeated in three times.

Spore germination assay. To study the effect of ANE on spore germination of $P$. aphanis, detached leaf assay was carried out as described in Feechan et al. (2015). Briefly, young fully expanded leaves of strawberry plant were sprayed with ANE or water, as described earlier. The leaves were excised after 48-h of the second treatment, and each leaf was placed with the adaxial surface up on a wet sterile paper in petri dishes. A total of six detached leaves were used per treatment and were replicated three times. For inoculation, leaves were tapped with freshly produced conidia, as described by Li et al. (2017). All Petri dishes were maintained at $25^{\circ} \mathrm{C}$. Forty-eight hour post-inoculation, the leaves were decholorophilized with solution containing acetic acid and ethanol (1:3). The decolorized leaves were 
stained with $10 \mathrm{ml}$ of trypan blue solution containing lactic acid:phenol:distilled water and glycerol (1:1:1:1) and $2 \mathrm{mg}$ of trypan blue for $1 \mathrm{~h}$. The small pieces of stained leaves were mounted in 50\% glycerol and observed under a microscope.

Powdery mildew disease assays. A water agar assay with detached leaves was done as described by Bieri et al. (2003) with minor modifications. Fully expanded leaves of strawberry plants were sprayed with ANE and water, as described earlier, and were excised along with intact petiole. For inoculation, leaves were tapped with freshly produced conidia, as described by Li et al. (2017). The leaf petiole was inserted in $2 \%$ water agar with $25 \mathrm{mg} / \mathrm{l}$ benzimidazole to prevent the early senescence of leaves as described by Hoseinzadeh et al. (2019). For the assessment of disease development, the individual leaf was measured for infected leaf area by Image $\mathrm{J}$ software (NIH, Bethesda, MD, USA) and suspended in distilled water for a spore count with a hemocytometer. Each treatment consisted of three leaves from six different plants and the experiment was repeated in triplicate.

Forty-eight hours after the second spray, the leaves were inoculated with fungal spores by tapping from infected leaves as described by Li et al. (2017). The disease severity data was recorded at 7 th and 15 th day post-inoculation (dpi) by measuring percent leaf area infected. A 1-6 rating scale was used for scoring disease severity on the leaves. The scoring scale was based on the visual estimation of percentage leaf area covered with powdery mildew (Cohen, 1993; Jayaraman et al., 2011), as follows: 1, no infection; 2, 1-19\% infected leaf surface; 3, 20-39\% infected leaf surface; 4, 40-59\% infected leaf surface; 5, 60-79\% infected leaf surface; and 6, 80-100\% infected leaf surface infected with spores. Disease severity was calculated by using the following formula described by Singh and Prithiviraj (1997).

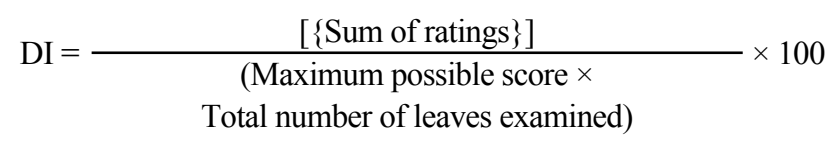

Determination of secondary metabolites. For the quantification of secondary metabolites, leaf samples were harvested at $24,48,72,96$, and $120 \mathrm{~h}$ post-inoculation. The leaf samples were also harvested from the uninoculated ANE sprayed plants at the same time point. The samples were frozen in liquid nitrogen and homogenized with a mortar and pestle. The fine frozen powder was immediately suspended in $80 \%$ methanol and centrifuged at 10,000 $\times g$ for $10 \mathrm{~min}$ at $4^{\circ} \mathrm{C}$. The supernatant was collected and sediment was again centrifuged by adding $10 \mathrm{ml}$ of $80 \%$ methanol at $10,000 \times g$ for $10 \mathrm{~min}$ at $4^{\circ} \mathrm{C}$ to make the final volume up to $30 \mathrm{ml}$.

The total phenolic content was determined using the Folin-Ciocalteu assay described by John et al. (2014). An aliquot $(1 \mathrm{ml})$ of plant extract or standard solution of gallic acid $(1,2,3,4,5,6$, and $7 \mu \mathrm{g} / \mathrm{ml})$ was added to a $25-$ $\mathrm{ml}$ volumetric flask containing $9 \mathrm{ml}$ of distilled water. A reagent blank was used with distilled water. One milliliter of $0.2 \mathrm{~N}$ Folin-Ciocalteu phenol reagent was added to the mixture and vortexed. Samples were incubated for $5 \mathrm{~min}$ at room temperature. After $5 \mathrm{~min}, 10 \mathrm{ml}$ of $7 \%$ sodium carbonate $\left(\mathrm{Na}_{2} \mathrm{CO}_{3}\right)$ solution was added to the mixture. The mixture was incubated for $90 \mathrm{~min}$ at room temperature. After incubation, the absorbance against the reagent blank was determined at $550 \mathrm{~nm}$ with a UV-Visible spectrophotometer. Total phenolic content was expressed as mg gallic acid equivalents (John et al., 2014).

Total flavonoid content was measured following the method described by John et al. (2014). An aliquot (1 ml) of plant extract or standard solutions of quercetin $(0,10$, $20,30,40,50,60,70$, and $80 \mu \mathrm{g} / \mathrm{ml}$ ) was added to a $10 \mathrm{ml}$ volumetric flask containing $4 \mathrm{ml}$ of distilled water. Then, 0.3 $\mathrm{ml}$ of $5 \%$ sodium nitrite $\left(\mathrm{NaNO}_{2}\right)$ was added to the flask and after $5 \mathrm{~min}$ of incubation at room temperature, $0.3 \mathrm{ml}$ of $10 \%$ aluminum chloride $\left(\mathrm{AlCl}_{3}\right)$ was added. After $5 \mathrm{~min}$, $2 \mathrm{ml}$ of $1 \mathrm{M}$ sodium hydroxide $(\mathrm{NaOH})$ was added and the volume was adjusted to $10 \mathrm{ml}$ with distilled water. The solution was vortexed and absorbance was taken against the blank at $510 \mathrm{~nm}$. The total flavonoid content was expressed as mg quercetin equivalents (John et al., 2014).

Determination of phenylalanine ammonia lyase activity. The effect of ANE on defense-related enzymes was studied. Plants were sprayed with ANE $(0.1 \%, 0.2 \%$, and $0.3 \%)$ until dripping and leaves were harvested $24,48,72,96$, and $120 \mathrm{~h}$ post-inoculation, weighed and frozen in liquid nitrogen. The phenylalanine ammonia lyase (PAL) activity was determined as described by Subramanian et al. (2011). Briefly, the leaf tissue was ground in $25 \mathrm{mM}$ borate buffer (pH 8.8) containing $0.5 \mathrm{~g} / 1$ polyvinylpyrrolidone (PVP). The homogenate was centrifuged at $12,000 \times g$ for $30 \mathrm{~min}$ at $4{ }^{\circ} \mathrm{C}$. The supernatant was used as the crude enzyme extract. The activity of PAL was estimated based on the amount of cinnamic acid formed with phenylalanine as the substrate following the protocol described by Subramanian et al. (2011). The amount of cinnamic acid was calculated using a standard graph of cinnamic acid and expressed as $\mu \mathrm{g}$ cinnamic $\mathrm{acid} / \mathrm{min} / \mathrm{mg}$ protein. 
Determination of peroxidase and polyphenol oxidase activity. Polyphenol oxidase (PPO) and peroxidase (PO) activity were determined as described by Ngadze et al. (2012). Briefly, the leaf tissue was homogenized in $0.05 \mathrm{M}$ sodium phosphate buffer containing $0.5 \mathrm{~g} / \mathrm{l} \mathrm{PVP}$. The homogenate was centrifuged at $13,000 \times g$ for $10 \mathrm{~min}$ at $4^{\circ} \mathrm{C}$. The supernatant was used as crude enzyme extract. PPO activity was assayed using catechol as substrate. The reaction mixture consists of $1 \mathrm{ml}$ crude extract, $2.9 \mathrm{ml}$ of 0.05 $\mathrm{M}$ sodium phosphate buffer and $1 \mathrm{ml}$ of $0.1 \mathrm{M}$ catechol (Sigma, St. Louis, MO, USA). The absorbance at $546 \mathrm{~nm}$ was recorded for $5 \mathrm{~min}$ in $30 \mathrm{~s}$ intervals. The PPO activity was expressed as absorbance/min/mg protein. PO activity was assayed using guaiacol as substrate. The reaction mixture consists of $1 \mathrm{ml}$ of crude extract, $2.9 \mathrm{ml}$ of $0.05 \mathrm{M}$ sodium phosphate buffer, $1 \mathrm{ml}$ of guaiacol and $1 \mathrm{ml}$ of $2 \%$ $\mathrm{H}_{2} \mathrm{O}_{2}$. The absorbance was recorded at $470 \mathrm{~nm}$ for $5 \mathrm{~min}$ at 30 -s intervals. PO activity was expressed as absorbance/ $\mathrm{min} / \mathrm{mg}$ protein.

Field experiments. To test the effect of ANE on powdery mildew of strawberry, a field trial was conducted at Great Village, NS. The field experiments were performed under natural infection. The experiments were completely randomized and repeated with four replications in each treatment ( 50 plants per treatment). The strawberry plants were sprayed with ANE $(0.1 \%, 0.2 \%$, and $0.3 \%)$ and water (control). Treatments were applied at 2-week intervals. The first symptoms of disease appeared 3 weeks after the first treatment spray. As soon as symptoms appeared on plants, severity of disease was assessed on infected leaves once a week for 4 weeks. A 0-4 rating scale was used for scoring disease severity on the leaves, as follows: 0 , no infection; 1 , partial infection on lower surface (1-24\%); 2 , complete infection on lower surface (25-49\%); 3, complete infection on lower surface and partial infection on upper surface of leaves (50-74\%); and 4, complete infection on both surface of leaves (75-100\%) (Table 1). Disease severity was calculated by using the following formula described by Singh and Prithiviraj (1997).

Table 1. Powdery mildew severity scale used in this study

\begin{tabular}{cc}
\hline Infection rating & Leaf area infection $(\%)$ \\
\hline 0 & No infection \\
1 & $1-24$ \\
2 & $25-49$ \\
3 & $50-74$ \\
4 & $75-100$ \\
\hline
\end{tabular}

Statistical analysis. All experiments were designed by Complete Randomized Design with three replicates. The field trial was designed by using Randomized Complete Block Design. All data were analyzed by using analysis of variance, with a $P$-value of $\leq 0.05$ using the "Proc. mixed procedure," of the SAS version 9.4 (SAS Institute, Inc., Cary, NC, USA). When significant effects of treatments were found, a multiple means comparison was carried out using Tukey's analysis, with a 95\% confidence interval and $\alpha=0.05$ to find means that are significantly different from others. The significantly different mean values were indicated by different letters.

\section{Results}

ANE reduces spore germination of $P$. aphanis and powdery mildew development on detached leaf. The effect of ANE on P. aphanis spore germination was evaluated on detached strawberry leaves sprayed with different con-

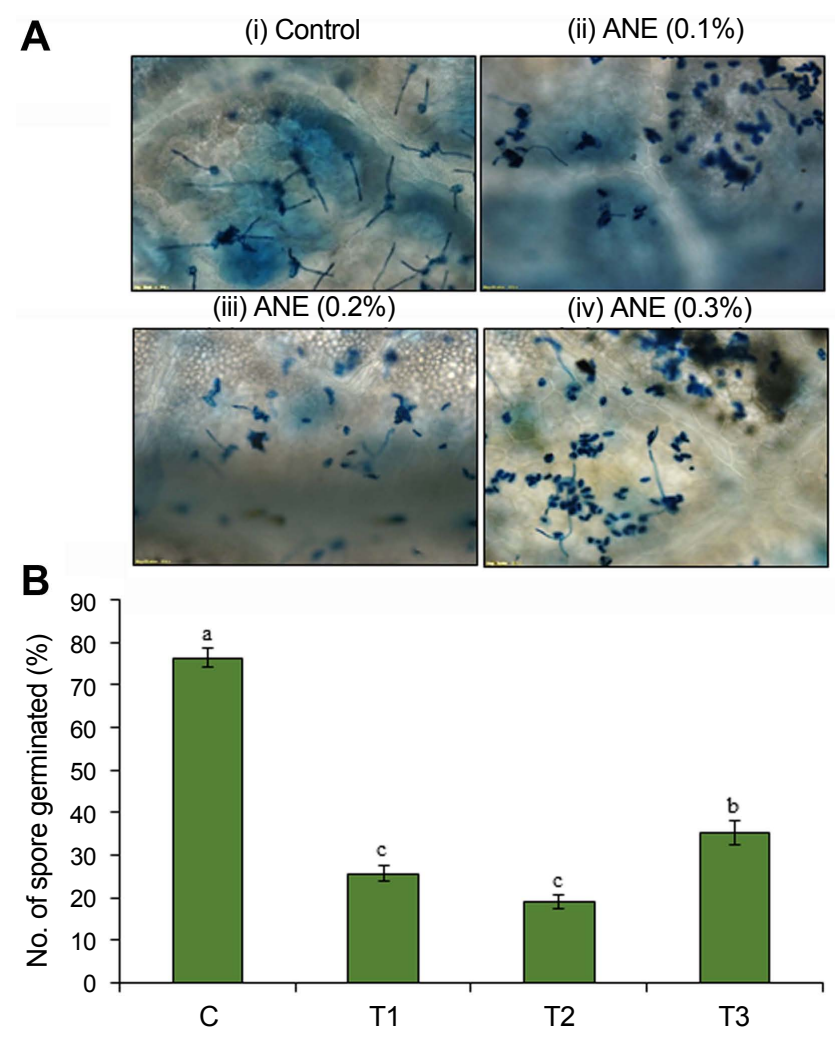

Fig. 1. The effect of foliar spray with Ascophyllum nodosum extract (ANE) on spore germination of Podosphaera aphanis in detached strawberry leaves. (A) Microscopic view of germinated spores in Trypan blue stained strawberry leaves sprayed with control, 0.1\% ANE, 0.2\% ANE, and 0.3\% ANE. (B) Percentage germination of $P$. aphanis on strawberry leaves sprayed with control (C), 0.1\% ANE (T1), 0.2\% ANE (T2), and 0.2\% ANE (T3). 
centrations of ANE $(0.1 \%, 0.2 \%$, and $0.3 \%)$. After 48 hpi (hours post-inoculation), the ANE sprayed leaves showed a significant reduction in the germination of spores compared to the control $(P \leq 0.05)$ (Fig. 1). Foliar application with $0.2 \%$ ANE significantly reduced the spore germination rate by $75 \%$, followed by a reduction of $66.3 \%$ in $0.1 \%$ ANE and $54 \%$ in $0.3 \%$ ANE sprayed leaves, as compared to the control (Fig. 1B).

The progression of disease on the detached leaf was recorded on 7th and 15th dpi by measuring the infected leaf

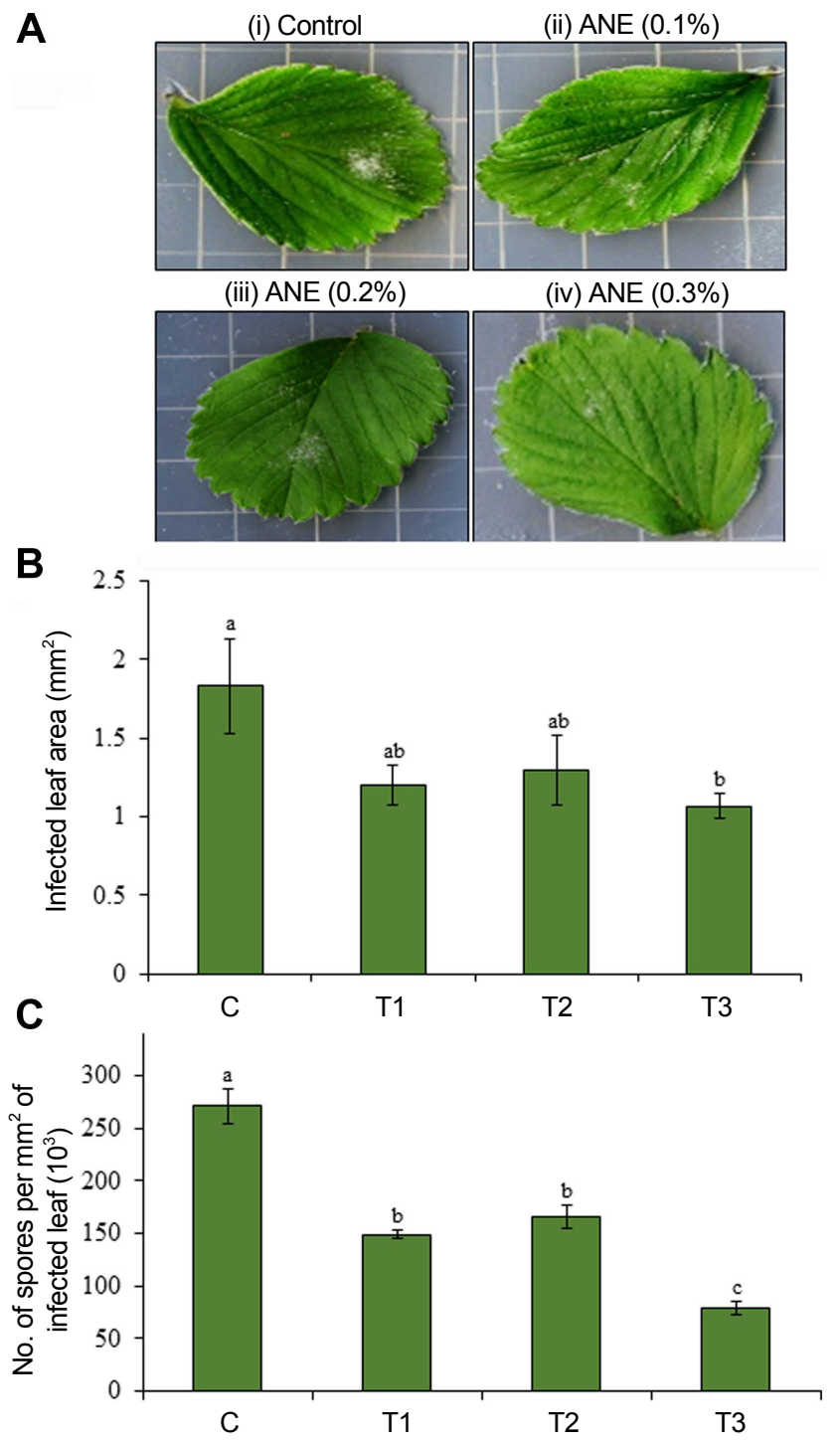

Fig. 2. (A) Foliar spray of Ascophyllum nodosum extract (ANE) reduces powdery mildew on detached leaves of strawberry placed on $2 \%$ water agar: control, $0.1 \%$ ANE, $0.2 \%$ ANE, and $0.3 \%$ ANE. This graph represents infected leaf area (B) and number of spores per $\mathrm{mm}^{2}$ (C) of infected leaf of strawberry sprayed with control (C), 0.1\% ANE (T1), 0.2\% ANE (T2), and 0.3\% ANE (T3).

area and counting the number of spores. Results showed that the control leaf had a larger diseased area, while ANE sprayed leaves had less infected area and showed significant reduction in progression of powdery mildew by reducing the growth of $P$. aphanis with lesser number of spores per infected leaves. The leaf area covered with powdery mildew was reduced by $34.36 \%, 29.1 \%$, and $42 \%$ in $0.1 \%$, $0.2 \%$, and $0.3 \%$ ANE treated leaves, respectively, as compared to the control (Fig. 2B and C). The spray of $0.3 \%$ ANE was most effective in reducing the powdery mildew infection in strawberry leaves (Fig. 2B and C).

A

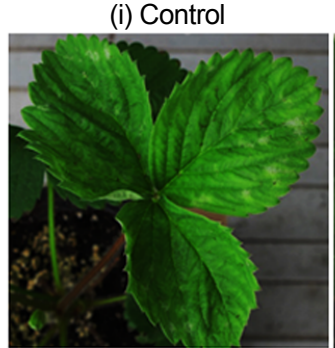

(iii) ANE (0.2\%)

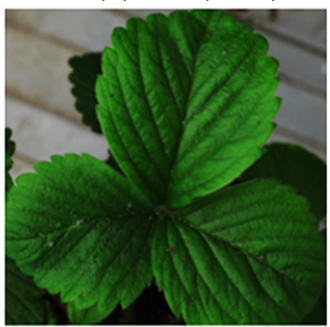

B

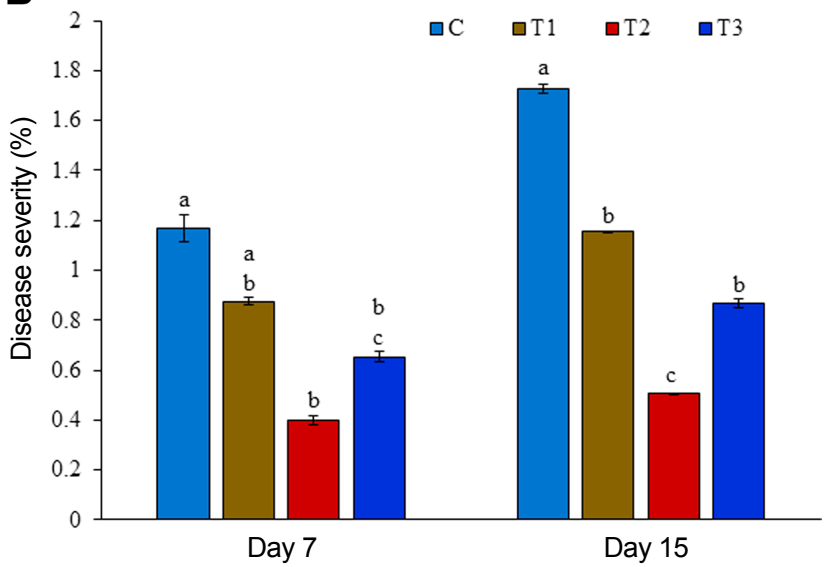

Fig. 3. The effect of foliar spray of Ascophyllum nodosum extract (ANE) on powdery mildew of strawberry plants grown in green house conditions. (A) Powdery mildew infection on strawberry plants sprayed with control, $0.1 \%$ ANE, $0.2 \%$ ANE, and $0.3 \%$ ANE. (B) This graph represents disease severity on 7 th and 15 th day of post inoculation with spores of Podosphaera aphanis in strawberry plants sprayed with control (C), 0.1\% ANE (T1), $0.2 \%$ ANE (T2), and 0.2\% ANE (T3). 
ANE reduces severity of powdery mildew in growth chamber grown strawberry plants. The effect of ANE treatment on powdery mildew disease severity in strawberry plants grown in the growth chamber was evaluated. Disease severity was recorded on 7 th and 15 th day after inoculation. ANE treatments showed reduced disease severity when compared with the control (Fig. 3A). Seven days' post-inoculation, the plants treated with $0.2 \%$ ANE showed maximum reduction in disease severity by $65.7 \%$, as compared to the control, while the reduction in disease severity was observed by $71 \%$, as compared to the control $15 \mathrm{dpi}$ (Fig. 3B). The control plants showed $48 \%$ increase of powdery mildew from day 7 to 15 , while $0.1 \%, 0.2 \%$, and $0.3 \%$ ANE treated, respectively, showed $32 \%, 27 \%$, and $32.4 \%$ increase in powdery mildew infection from day 7 to 15 . Thus, spray of $0.2 \%$ ANE not only reduces the incidence of powdery mildew, but also prevents its progression.

ANE induces change in the phenolic and flavonoid content in the strawberry leaves infected with powdery mildew. The results presented in this study revealed that ANE sprayed plants showed significantly higher flavonoid content, as compared to the control plants. After $120 \mathrm{~h}$, the
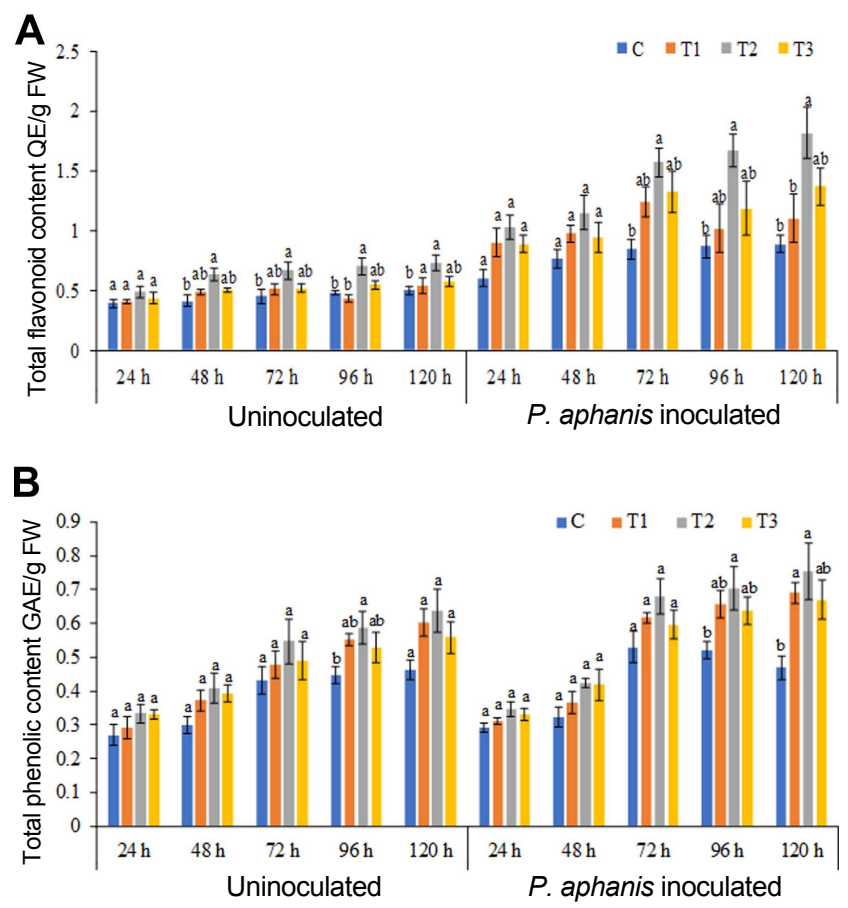

Fig. 4. The effect of Ascophyllum nodosum extract (ANE) on total flavonoid content (A), and total phenolic content (B) of strawberry leaves sprayed with control (C), 0.1\% ANE (T1), 0.2\% ANE (T2), and $0.2 \%$ ANE (T3), and strawberry leaves sprayed with control (C), 0.1\% ANE (T1), 0.2\% ANE (T2), and $0.2 \%$ ANE (T3) in response to powdery mildew infection. maximum flavonoid content was recorded in $0.2 \%$ ANE sprayed leaves, which was $47.2 \%$ higher than the control plants (Fig. 4A). P. aphanis infection increased the flavonoid content in both control and ANE treated plants. The flavonoid content was higher in all ANE sprayed leaves inoculated with pathogen $(0.1 \%, 0.2 \%$, and $0.3 \%)$, as compared to the control as well as ANE treated uninoculated leaves. Leaves sprayed with $0.2 \%$ ANE showed maximum increase in total flavonoid after $120 \mathrm{~h}$ of post-inoculation with $P$. aphanis (Fig. 4A). Spray of ANE induced the phenolics production in the strawberry plants (Fig. 4B). Powdery mildew infection increased the phenolic content in strawberry plants from 24 to $120 \mathrm{~h}$ post-inoculation in all the treatments. Total phenolic concentration was increased
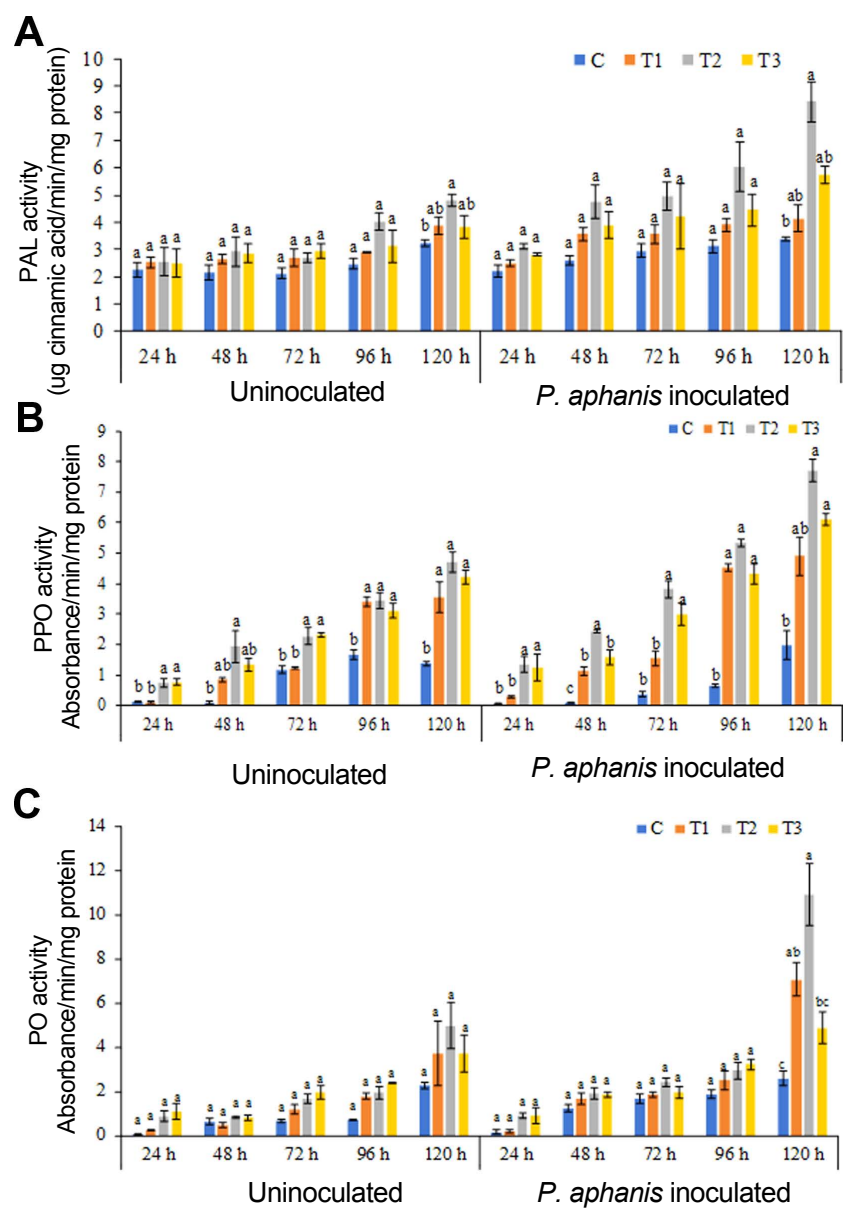

Fig. 5. Defense-related enzyme activities in strawberry plants sprayed with different concentrations of Ascophyllum nodosum extract (ANE). (A) Phenylalanine ammonia lyase (PAL). (B) Polyphenol peroxidase (PPO). (C) Peroxidase (PO) activities in plants sprayed with control (C), T1 (0.1\% ANE), 0.2\% ANE (T2), and $0.2 \%$ ANE (T3), and strawberry leaves sprayed with control (C), 0.1\% ANE (T1), 0.2\% ANE (T2), and 0.2\% ANE (T3) in response to powdery mildew infection. 
by $30 \%, 51.5 \%$, and $14 \%$, respectively, in $0.1 \%, 0.2 \%$, and $0.3 \%$ ANE sprayed strawberry plants, as compared to the control after $120 \mathrm{~h}$ post-inoculation with spore of $P$. aphanis (Fig. 4B).

ANE modulates the activity of defense-related enzymes in response to powdery mildew infection in strawberry. The effect of ANE treatment on the induction of defense enzymes PAL, PO, and PPO in strawberry leaf was studied. Foliar spray with ANE induced PAL activity in ANE sprayed uninoculated plants (Fig. 5A). The maximum activity of PAL was induced in plants treated with $0.2 \%$ ANE (Fig. 5A). Inoculation of pathogen on the ANE sprayed leaves further induces PAL activity. The maximum induction of PAL was observed $120 \mathrm{~h}$ post-inoculation in $0.2 \%$ ANE treated plants. Similarly, pathogen inoculation also induces PO and PPO activity as compared to the control and uninoculated plants. Maximum activities of PPO and PO were observed after $120 \mathrm{~h}$ of treatment (Fig. 5B and C). Thus, plants treated with ANE induce the defense-related enzymes and improves plant resistance against powdery mildew infection.

ANE reduces severity of powdery mildew in the fieldgrown strawberry. The field experiment was carried out from June 2016 to September 2016 at a commercial field located in Great Village, Nova Scotia, Canada. Three concentrations of ANE $(0.1 \%, 0.2 \%$, and $0.3 \%)$ were sprayed until drip. After the occurrence of natural infection of powdery mildew, observations were recorded every 7 days since the first occurrence of the disease. The incidence of powdery mildew was $82 \%$ in the control treatment, while

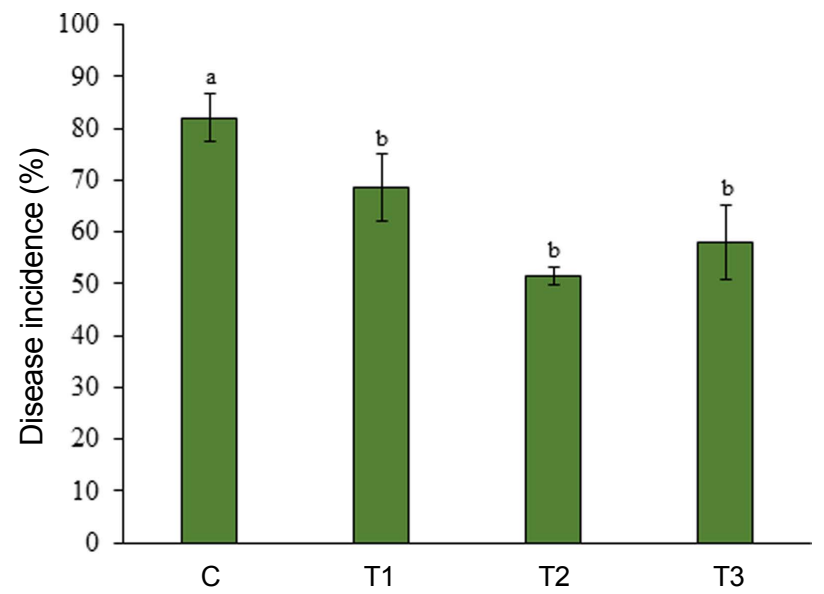

Fig. 6. Natural incidence of powdery mildew on strawberry plants sprayed with control (C), $0.1 \%$ Ascophyllum nodosum extract (ANE) (T1), 0.2\% ANE (T2), and 0.2\% ANE (T3) under field conditions. the incidence of disease reduced to $68.5 \%, 51.5 \%$, and $58 \%$, respectively, in $0.1 \%, 0.2 \%$, and $0.3 \%$ ANE treatments (Fig. 6). The $0.2 \%$ ANE treatment showed the maximum reduction of powdery mildew by $37.2 \%$ as compared to control. Powdery mildew severity was reduced to $47.2 \%$, $47.1 \%$, and $51.2 \%$, respectively, in $0.1 \%, 0.2 \%$, and $0.3 \%$ ANE sprayed plants, as compared to control plants on day 1 (Fig. 7). As time progressed, the disease also progressed in both the control and treated plants from day 1 to 7 , but, disease progression was significantly reduced by $34.3 \%$ in $0.1 \%$ ANE treated plants and $32 \%$ in 0.2 and $0.3 \%$ ANE treated plants (Fig. 7). After day 14 of disease incidence, reduction in disease was observed in both the control and treated plants. Lower nighttime temperatures in August are not favorable for powdery mildew (compared with earlier summer months), therefore, leading to the reduction of disease under the natural field conditions.

\section{Discussion}

The use of synthetic chemical pesticides for the management of plant diseases has adverse impacts on human health and the environment. Several sustainable alternatives for plant disease management have been proposed. The elicitor molecules present in seaweed extracts enhance plant defenses against various pathogens (Burketova et al., 2015; Khan et al., 2009). Several reports show that ANE acts as a potential elicitor and possesses disease suppressive activities (Jayaraman et al., 2011; Khan et al., 2009). The ANE has been known to suppress diseases in several plants such as Arabidopsis, carrot, cucumber and tomato (Abkhoo and Sabbagh, 2016; Ali et al., 2016; Jayaraj et al., 2008; Jayaraman et al., 2011; Subramanian et al., 2011). Previously published reports suggest that ANE induces plant defense systems against broad ranges of pathogens (Khan et al., 2009).

In this study, we showed that the foliar spray of ANE elicited defense responses in strawberry against $P$. aphanis. Microscopic observations revealed that the germination of the fungal spore was significantly reduced in ANE sprayed plants. The elicitor molecules like laminarin and fucoidans present in ANE acts as PAMPs due to their structural similarity to the constituents of pathogen cell wall, and these PAMPs are recognized by host transmembrane PRRs, which serves as an endogenous signal to activate plant immune responses and primed the plants against disease (Eckardt, 2008; Zipfel, 2009). This might be the reason there was reduced germination of powdery mildew conidia and development of the disease on ANE treated plants. The effect of ANE in reducing the powdery mildew infection 


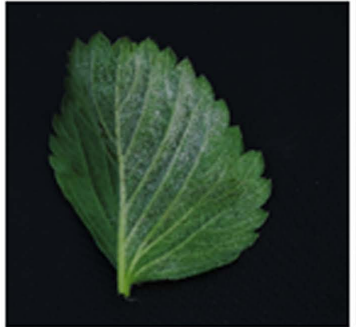

Partial infection on lower surface (1)

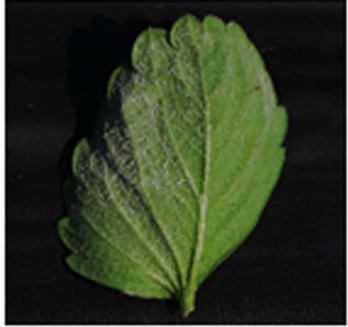

Complete infection on lower surface (2)
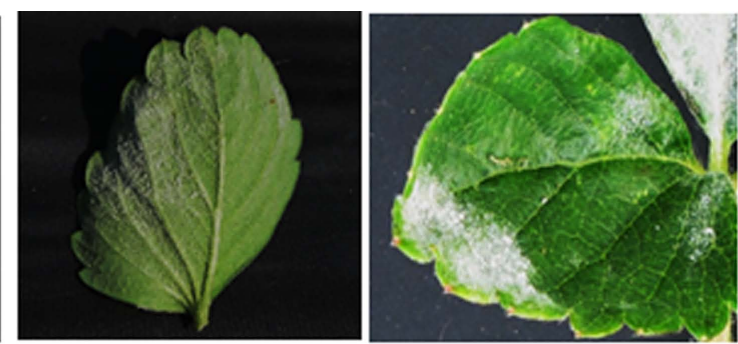

Complete infection on lower and partial on upper surface (3)

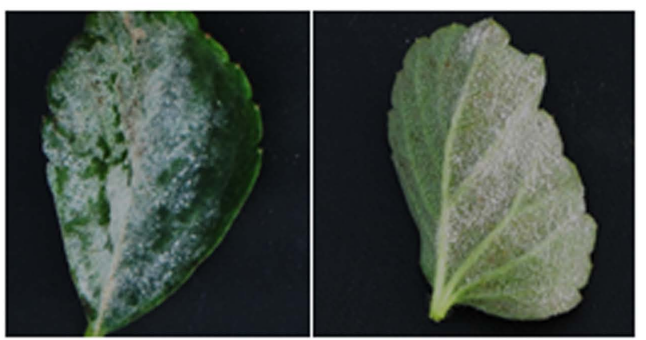

Complete infection on both surface (4)

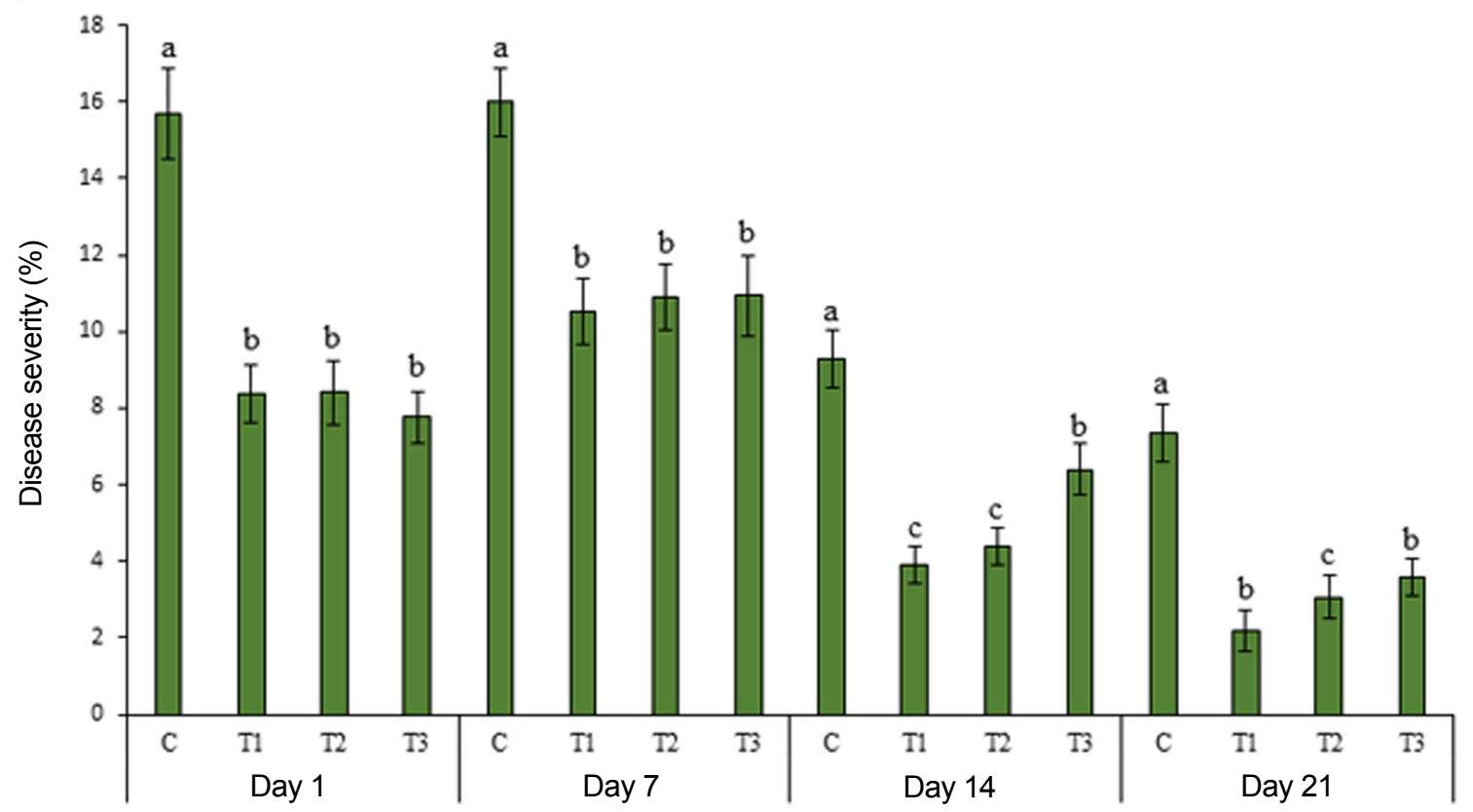

Fig. 7. Disease severity of powdery mildew observed every 7 days for 1 month after the natural occurrence of disease on strawberry plants sprayed with control (C), 0.1\% Ascophyllum nodosum extract (ANE) (T1), 0.2\% ANE (T2), and 0.2\% ANE (T3) under field conditions.

was observed in both the greenhouse as well as in natural field conditions, suggesting that ANE is capable of inducing pathogen resistance irrespective of the growing conditions.

Strawberry resistance to powdery mildew depends on the intricate network of constitutive and inducible defense responses (Amil-Ruiz et al., 2011). Several secondary me- tabolites play an important role in plant's defense against pathogens by direct toxicity on the pathogen or act as a precursor to physical defense systems (Bennet and Wallsgrove, 1994). These secondary metabolites form biological chemical barriers and act locally at the early stage of infection (Kliebenstein, 2004). Elicitors induce the accumulation of secondary metabolites in response to pathogen attack 
(Zhao et al., 2005). In this study, the effect of ANE on the accumulation of different secondary metabolites in strawberry plants was evaluated in response to powdery mildew infection. Foliar application of ANE increased the concentration of phenolics in strawberry plants in response to powdery mildew infection. Similarly, Stimplex, a commercial product from A. nodosum showed higher phenolic content in cucumber in response to a different fungal pathogen (Jayaraman et al., 2011). A similar effect of ANE on phenolic content was observed in carrot in response to Alternaria radicina and Botrytis cinerea infection (Jayaraj et al., 2008). Strawberry plants are the natural source of various phenolic compounds such as ellagitannins and ellagic acid (Aaby et al., 2005, 2007). Flavonoids are actively synthesized in the strawberry plants that induce disease resistance (Amil-Ruiz et al., 2011; Treutter, 2006). In this study, the foliar spray of ANE leads to the accumulation of flavonoids in the strawberry plants and suppresses the progression of powdery mildew infection. Several published reports have also found a positive correlation between resistance to plant pathogens and the concentration of flavonoids (AmilRuiz et al., 2011; Treutter, 2006). Strawberry cultivars with higher flavonoid content were found to be more resistant to pathogen infection (Amil-Ruiz et al., 2011). Thus, elicitors present in ANE stimulate the production of phenolic and flavonoid compounds and contribute to the strawberry's active defense against powdery mildew infection.

The enhanced accumulation of phenolics and flavonoids was due to increased activity of defense-related enzymes such as PAL, PPO, and PO. PAL, an enzyme involved in secondary phenylpropanoid metabolism, plays an important role in plant's response to pathogens (Kim and Hwang, 2014). In this study, the bioactive component of ANE elicited the activity of PAL in the strawberry leaves and conferred resistance against powdery mildew. Similarly, PO and PPO, which are involved in biosynthesis of oxidative phenols, and contribute to the plant's active defense against pathogenic infestation (Chen et al., 2000). The application of ANE induced resistance against powdery mildew by inducing the activity of PO and PPO involved in the biosynthesis of polyphenols. The induction of defense-related enzymes including PAL, PO, and PPO was observed $72 \mathrm{~h}$ post-inoculation, and further increased up to $120 \mathrm{~h}$ in ANE treated plants. Several studies showed that the elicitation of resistance against fungal pathogens by seaweed extract was mediated by an increase in PAL, PO, and PPO activity (apple, cucumber, carrot, and tomato) (Ali et al., 2016; Hernández-Herrera et al., 2014; Jayaraj et al., 2008; Jayaraman et al., 2011). In these studies, the increased plant's resistance to different pathogens was marked by the en- hanced activity and expression of different defense-related genes involved in the accumulation of secondary metabolites.

Under field trials, the foliar spray of ANE reduces the incidence as well as severity of disease. This suggests that ANE reduces the powdery mildew in both the laboratory as well as field conditions. Together these results suggest that ANE elicits defense responses in strawberry plants against powdery mildew by regulating the biosynthesis of secondary metabolites and activities of different defense-related enzymes.

In conclusion, this study showed that the extract from $A$. nodosum reduces the progression of powdery mildew infection in the laboratory as well in the field. The use of extracts from ANE for management of powdery mildew minimizes the use of chemical-based fungicides and provides an environmentally safe and sustainable method for the management of fungal diseases in strawberry and other fruit crops. The results presented here are promising but to realize the full potential of ANE in eliciting the defense response and to implement ANE with disease management programs, a more comprehensive understanding of the mode of action of ANE on plant defense pathways is required.

\section{Acknowledgments}

The work reported in this paper was partly funded by Nova Scotia Department of Agriculture and MITACS. The authors are grateful to Emily Peters (Dalhousie University, Faculty of Agriculture) for the valuable suggestions in preparing the manuscript.

\section{References}

Aaby, K., Ekeberg, D. and Skrede, G. 2007. Characterization of phenolic compounds in strawberry (Fragaria $\times$ ananassa) fruits by different HPLC detectors and contribution of individual compounds to total antioxidant capacity. J. Agric. Food Chem. 55:4395-4406.

Aaby, K., Skrede, G. and Wrolstad, R. E. 2005. Phenolic composition and antioxidant activities in flesh and achenes of strawberries (Fragaria ananassa). J. Agric. Food Chem. 53:40324040.

Abkhoo, J. and Sabbagh, S. K. 2016. Control of Phytophthora melonis damping-off, induction of defense responses, and gene expression of cucumber treated with commercial extract from Ascophyllum nodosum. J. Appl. Phycol. 28:1333-1342.

Ali, N., Ramkissoon, A., Ramsubhag, A. and Jayaraj, J. 2016. Ascophyllum extract application causes reduction of disease levels in field tomatoes grown in a tropical environment. 
Crop. Prot. 83:67-75.

Amil-Ruiz, F., Blanco-Portales, R., Muñoz-Blanco, J. and Caballero, J. L. 2011. The strawberry plant defense mechanism: a molecular review. Plant Cell Physiol. 52:1873-1903.

Bennett, R. N. and Wallsgrove, R. M. 1994. Secondary metabolites in plant defence mechanisms. New Phytol. 127:617-633.

Bieri, S., Potrykus, I. and Fütterer, J. 2003. Effects of combined expression of antifungal barley seed proteins in transgenic wheat on powdery mildew infection. Mol. Breed. 11:37-48.

Burketova, L., Trda, L., Ott, P. G. and Valentova, O. 2015. Biobased resistance inducers for sustainable plant protection against pathogens. Biotechnol. Adv. 33:994-1004.

Chen, C., Bélanger, R. R., Benhamou, N. and Paulitz, T. C. 2000. Defense enzymes induced in cucumber roots by treatment with plant growth-promoting rhizobacteria (PGPR) and $P y$ thium aphanidermatum. Physiol. Mol. Plant Pathol. 56:1323.

Cohen, R. 1993. A leaf disk assay for detection of resistance of melons to Sphaerotheca fuliginea race 1. Plant Dis. 77:513517.

Corke, A. T. and Jordan, V. W. 1978. Powdery mildews of bush and soft fruits. In: The powdery mildews, ed. by D. M. Spencer, pp. 347-358. Academic Press, London, UK.

De Cal, A., Redondo, C., Sztejnberg, A. and Melgarejo, P. 2008. Biocontrol of powdery mildew by Penicillium oxalicum in open-field nurseries of strawberries. Biol. Control 47:103107.

Dogra, B. S. and Mandradia, R. K. 2014. Effect of seaweed extract on growth and yield of onion. Int. J. Farm Sci. 2:59-64.

Eckardt, N. A. 2008. Chitin signaling in plants: insights into the perception of fungal pathogens and rhizobacterial symbionts. Plant Cell 20:241-243.

Elmhirst, J. 2005. Crop profile for strawberry in Canada. Report produced by Pesticide Risk Reduction Program, Pest Management Centre, Agriculture and Agri-Food Canada, Ottawa, Canada. URL http://publications.gc.ca/collections/collection_2009/agr/A118-10-17-2005E.pdf [26 March 2019].

El-Miniawy, S. M., Ragab, M. E., Youssef, S. M. and Metwally, A. A. 2014. Influence of foliar spraying of seaweed extract on growth, yield and quality of strawberry plants. J. Appl. Sci. Res. 10:88-94.

Feechan, A., Kocsis, M., Riaz, S., Zhang, W., Gadoury, D. M., Walker, M. A., Dry, I. B., Reisch, B. and Cadle-Davidson, L. 2015. Strategies for RUN1 deployment using RUN2 and $R E N 2$ to manage grapevine powdery mildew informed by studies of race specificity. Phytopatholology 105:1104-1113.

Hernández-Herrera, R. M., Virgen-Calleros, G., Ruiz-López, M., Zañudo-Hernández, J., Délano-Frier, J. P. and SánchezHernández, C. 2014. Extracts from green and brown seaweeds protect tomato (Solanum lycopersicum) against the necrotrophic fungus Alternaria solani. J. Appl. Phycol. 26:1607-1614.

Holdt, S. L. and Kraan, S. 2011. Bioactive compounds in seaweed: functional food applications and legislation. J. Appl.
Phycol. 23:543-597.

Hoseinzadeh, P., Zhou, R., Mascher, M., Himmelbach, A., Niks, R. E., Schweizer, P. and Stein, N. 2019. High resolution genetic and physical mapping of a major powdery mildew resistance locus in barley. Front. Plant Sci. 10:146.

Ilangumaran, G., Stratton, G., Ravichandran, S., Shukla, P. S., Potin, P., Asiedu, S. and Prithiviraj, B. 2017. Microbial degradation of lobster shells to extract chitin derivatives for plant disease management. Front. Microbiol. 8:781.

Jayaraj, J., Wan, A., Rahman, M. and Punja, Z. K. 2008. Seaweed extract reduces foliar fungal diseases on carrot. Crop Prot. 27:1360-1366.

Jayaraman, J., Norrie, J. and Punja, Z. K. 2011. Commercial extract from the brown seaweed Ascophyllum nodosum reduces fungal diseases in greenhouse cucumber. J. Appl. Phycol. 23:353-361.

John, B., Sulaiman, C. T., George, S. and Reddy, V. R. K. 2014. Total phenolics and flavonoids in selected medicinal plants from Kerala. Int. J. Pharm. Pharm. Sci. 6:406-408.

Karajeh, M. R., Al-Rawashdeh, Z. B. and Al-Ramamneh, E. A.-D. M. 2012. Occurrence and control of strawberry powdery mildew in Al-Shoubak/Jordan. Jordan J. Agric. Sci. 8:380-390.

Khan, W., Rayirath, U. P., Subramanian, S., Jithesh, M. N., Rayorath, P., Hodges, D. M., Critchley, A. T., Craigie, J. S., Norrie, J. and Prithiviraj, B. 2009. Seaweed extracts as biostimulants of plant growth and development. J. Plant Growth Regul. 28:386-399.

Kim, D. S. and Hwang, B. K. 2014. An important role of the pepper phenylalanine ammonia-lyase gene (PAL1) in salicylic acid-dependent signalling of the defence response to microbial pathogens. J. Exp. Bot. 65:2295-2306.

Kiss, L. 2003. A review of fungal antagonists of powdery mildews and their potential as biocontrol agents. Pest Manag. Sci. 59:475-483.

Kliebenstein, D. J. 2004. Secondary metabolites and plant environment interactions: a view through Arabidopsis thaliana tinged glasses. Plant Cell Environ. 27:675-684.

Li, N., Jia, H., Kong, Z., Tang, W., Ding, Y., Liang, J., Ma, H. and Ma, Z. 2017. Identification and marker-assisted transfer of a new powdery mildew resistance gene at the Pm4 locus in common wheat. Mol. Breed. 37:79.

Maas, J. L. 1998. Compendium of strawberry diseases. 2nd ed. APS Press, St. Paul, MN, USA. 98 pp.

Mercier, L., Lafitte, C., Borderies, G., Briand, X., EsquerréTugayé, M.-T. and Fournier, J. 2001. The algal polysaccharide carrageenans can act as an elicitor of plant defence. New Phytol. 149:43-51.

Nezhadahmadi, A., Faruq, G. and Rashid, K. 2015. The impact of drought stress on morphological and physiological parameters of three strawberry varieties in different growing conditions. Pak. J. Agric. Sci. 52:79-92.

Ngadze, E., Icishahayo, D., Coutinho, T. A. and van der Waals, J. E. 2012. Role of polyphenol oxidase, peroxidase, phenylalanine ammonia lyase, chlorogenic acid, and total soluble phe- 
nols in resistance of potatoes to soft rot. Plant Dis. 96:186192.

Patier, P., Potin, P., Rochas, C., Kloareg, B., Yvin, J.-C. and Liénart, Y. 1995. Free or silica-bound oligokappa-carrageenans elicit laminarinase activity in Rubus cells and protoplasts. Plant Sci. 110:27-35.

Sharma, H. S. S., Fleming, C., Selby, C., Rao, J. R. and Martin, T. 2014. Plant biostimulants: a review on the processing of macroalgae and use of extracts for crop management to reduce abiotic and biotic stresses. J. Appl. Phycol. 26:465-490.

Shukla, P. S., Borza, T., Critchley, A. T. and Prithiviraj, B. 2016. Carrageenans from red seaweeds as promoters of growth and elicitors of defense response in plants. Front. Mar. Sci. 3:81.

Singh, U. P. and Prithiviraj, B. 1997. Neemazal, a product of neem (Azadirachta indica), induces resistance in pea (Pisum sativum) against Erysiphe pisi. Physiol. Mol. Plant. Pathol. 51:181-194.
Statistics Canada. 2015. Statistical overview of the Canadian fruit indistry 2015. URL http://www.agr.gc.ca/resources/prod/doc/ pdf/fruit report 2015-en.pdf [26 March 2019].

Subramanian, S., Sangha, J. S., Gray, B. A., Singh, R. P., Hiltz, D., Critchley, A. T. and Prithiviraj, B. 2011. Extracts of the marine brown macroalga, Ascophyllum nodosum, induce jasmonic acid dependent systemic resistance in Arabidopsis thaliana against Pseudomonas syringae pv. tomato DC3000 and Sclerotinia sclerotiorum. Eur. J. Plant Pathol. 131:237248.

Treutter, D. 2006. Significance of flavonoids in plant resistance: a review. Environ. Chem. Lett. 4:147.

Zhao, J., Davis, L. C. and Verpoorte, R. 2005. Elicitor signal transduction leading to production of plant secondary metabolites. Biotechnol. Adv. 23:283-333.

Zipfel, C. 2009. Early molecular events in PAMP-triggered immunity. Curr. Opin. Plant. Biol. 12:414-420. 